\title{
85674 - CARACTERÍSTICAS DO AUTOCUIDADO EM SAÚDE ORAL ENTRE IDOSOS RURAIS E URBANOS
}

\author{
Pôster - Gerontologia
}

Rejane Eliete Luz Pedro / Pedro, REL / PUCRS; Josemara de Paula Rocha / Rocha, JP / PUCRS; Renata Breda Martins / Martins, RB / PUCRS; Ângelo José Gonçalves Bós / Bós, AJG / PUCRS

Introdução: As condições de saúde oral da população idosa brasileira encontram-se em situação precária ${ }^{1}$. higiene, doenças da gengiva e até o desenvolvimento do câncer, se relacionam com as técnicas corretas de higiene bucal e ao autocuidado na cavidade oral ${ }^{2}$. Objetivo: Verificar as características do autocuidado em saúde oral entre idosos rurais e urbanos, através da Pesquisa Nacional de Saúde (PNS), dados de 2013. Método: Trata-se de um estudo transversal analítico de um banco de dados público oriundo da PNS, realizada pelo Instituto Brasileiro de Geografia e Estatística, em 2013. Foram selecionadas as informações dos indivíduos idosos (60 anos ou mais) em relação ao autocuidado em saúde oral e o local do domicílio dos idosos. Resultados: Dos 10.175 indivíduos idosos que responderam as questões de autocuidado bucal, observou-se que idosos urbanos apresentaram maiores frequências de escovação dental diária (2x ou mais) 83,78\% ( $\mathrm{n}=6.997$ ), uso de escova 99,24\% ( $\mathrm{n}=8.252)$, pasta dental 99,10\% ( $\mathrm{n}=8.240)$, fio dental 33,47\% ( $\mathrm{n}=2.783)$, e uma menor periodicidade de troca de escova dental, de uma vez ao ano ou nunca trocou 3,52\% $(n=293)$ em relação aos idosos rurais. Observou-se diferenças estatisticamente significativas entre os idosos rurais e urbanos $(\mathrm{p}<0,001)$. Conclusão: Idosos urbanos mostraram melhor autocuidado com relação a saúde oral do que idosos rurais. Torna-se importante a educação para a saúde, visando à promoção e prevenção da saúde oral dos idosos independente da sua área de moradia.

Palavras-chave: saúde oral, idosos urbanos, idosos rurais.

Referências: 1. DUTRA, C.E.S.V.; SANCHEZ, H.F. Organização da atenção à saúde bucal prestada ao idoso nas equipes de saúde bucal da Estratégia Saúde da Família. Revista Brasileira de Geriatria e Gerontologia, Rio de Janeiro. v. 18, n. 1, p. 179-188. 2015; 2. NETO, Nicolau Silveira, LUFT, Luciele Raquel. Condições de saúde bucal do idoso: revisão de literatura RBCEH, Passo Fundo, v. 4, n. 1, p. 48-56, jan./jun. 2007. 